\title{
Design Ethics of Eastern Hubei’s Rice Farming Implements in the Cultural Heritage and Its Expression of Folk Culture*
}

\author{
Jun Sun \\ Huanggang Normal University \\ Huangzhou, China 438000
}

\author{
Chunni $\mathrm{Xu}$ \\ Huanggang Normal University \\ Huangzhou, China 438000
}

\begin{abstract}
In this paper, the typical rice farming implements in Eastern Hubei are placed into the system of implements design as the point. Through the analysis on the cases of traditional farming implements in Eastern Hubei, the design and aesthetics of traditional farming implements in Eastern Hubei are discussed, from which the expression of folk culture in the folk heritage of the farming implements is understood, the historical value as well as the inheritance and communication value of Eastern Hubei's rice farming culture heritage are summarized, and the point which may enlightenment of the modern agricultural design is put forward.
\end{abstract}

Keywords-Eastern Hubei; implements; rice farming implements; folk culture

\section{INTRODUCTION}

Located in "the head of $\mathrm{Wu}$ and the end of Chu", Eastern Hubei adjoins the Province of Henan, Anhui, and Jiangxi. It is next to Dabie Mountain in the north and Yangtze River in the south. With four distinctive seasons, abundant rainfall, and warm and moist climate, it is the pore passage for going eastwards from the central region of the Yangtze River basin. It has relatively independent culture and geography since the ancient time. Since song dynasty, especially Ming dynasty, a developed agricultural cultural tradition has been formed here. For thousands of years, there has been a firm "agriculture-oriented" concept, and the hosts living here have written an "epic" memory of farming culture. As an important component in the design of traditional Chinese implements, the traditional farming implements in Eastern Hubei are deemed as an important carrier of China's traditional design thought and design culture, which contain both material and spiritual meanings, reflect and express the concept of "valuing agriculture" in the humanistic thoughts of Eastern Hubei. Through investigating and sorting the traditional farming implements and production activities in Eastern Hubei, the relationship between the essence of the simple and loyal creation thought in the folk of Eastern

*This article is the research achievement of the Stage of "Rural Traditional Craftsman Ethics - Drawings Sorting and Culture Research on Eastern Hubei's Farming and Production Implements (17YJC760073)" under the 2017 Youth Project for Humanities \& Social Sciences of the Ministry of Education. (Please annotate).
Hubei and the design ethics is perceived.

\section{THE "SIMPLE AND LOYAL" DESIGN BEAUTY OF EASTERN HUBEI'S RICE FARMING IMPLEMENTS}

Design refers to all innovative creation activities, which not only pay attention to beautification but also pay more attention to rationality and innovation. The traditional farming implements in Eastern Hubei are ordinary and plain, which often make people turn a blind eye to them and ignore their charm and truth. For example, the water-drawing implement closely related to people's life can be used for irrigation in agriculture, and can be used for extracting mineral sand and bittern in industry. Having great popularity and strong vitality, it directly reflects and maintains the most fundamental and simple geographical features.

\section{A. "Aesthetic" and "Simple" Material Selection}

The most important part of the design is the selection of materials, which is the foundation of the processing and production of farming implements, and meanwhile determines the production process, use efficiency and service life. The Book of Diverse Crafts has made reference to the standard of material selection: "The shaft should be based on three principles: First, it should be aesthetic. Second, it should have a long service life. Third, it should be sharp."1 Here, the standard of material selection is mentioned "aesthetic". In other words, the material selection should be pleasing to the eye, which is also suitable to the traditional rice farming implements. As a hilly land rice-growing area which is rich in all kinds of bamboo and wood, Eastern Hubei has a long history of rice cultivation. In the various production links such as sowing, fertilization, irrigation, harvesting, processing, storage and etc, the bamboo and wood farming implements are all involved. Most of these farming implements obtain materials from local resources, and are practical and convenient in the functions, shape and structure. For example, as one of the important farming implements in the rice growing area of Eastern Hubei, dumpers are mostly made by miscellaneous hardwood as they need to be soaked in the water for a long time. There are

Wen Renjun: Notes to the Book of Diverse Crafts [M], Shanghai: Shanghai Classics Publishing House, 1993. 
dense firs, foam resistant ashes, distortion-free elms, tensile mulberry, and etc growing in Eastern Hubei. Various kinds of trees with material simple and unadorned, property rich in toughness, and texture pleasing to the eye can meet the production requirements on the components in each part of dumpers. The nan bamboo and mao bamboo growing in Eastern Hubei are very good materials for making rice farming implements, which are well known for their light weight and durability. The narration cage, which people often use for soaking seed, is made of the skin and split of flexible, durable and tough nan bamboo, which can fully meet the needs of the rice seeds having larger volume after water absorption and expansion. Rice farming implements in Eastern Hubei originate from the folk production and life. In the material selection, people adhere to the characteristics of "obtaining materials from local sources, practical and convenient", which reflect the unsophisticated and primitive "simplicity" essence, and highlight the beauty of materials. It is the combination of "technology" and "art", reflecting people's understanding of nature and embodying the harmony of human with the nature, and is an important carrier of perceptual aesthetics. At the same time, the material making thought of "the unity of man and nature" reveals the Eastern Hubei people's philosophy of "advocating the nature and conforming to the nature".

\section{B. "Easy" and "Labor-saving" Operation}

As a design of "beauty", the implements must be designed to have "simple and convenient" operation. If a hoe has a handle surface which not polished smooth and often cuts fingers when using, such hoe will certainly not be used for a long time. So it cannot achieve due practical function. The traditional rice farming implements in Eastern Hubei has simple and convenient operation. An operation which can be realized by two steps will never have three steps. Taking the water-drawing implements in Eastern Hubei as an example, the rice field cannot be cultivated without water-drawing and irrigation. As the description in the Agricultural Administration Book - The Illustrated Handbook of Shadoof from Xu Guangqi, "Shadoof, is the implement for drawing water." It is a water-drawing implement utilizing the pitching principle of lever. Two upright bamboo poles are used as the support. Another bamboo pole is used as the balance pole. Two bamboo poles are erected at both ends for falling stones and hanging buckets. With simple and ingenious structure, its mechanical principle is: "force $\times$ arm of force" = "gravity $\times$ arm of gravity". As the water-drawing implement will be as heavy as dozens of and even a hundred catties (one catty = 0.5 kilogram) after it is filled with water, people is unable to lift it just by their arms. However, by virtue of the gravity of falling stones, people can lift the water-drawing implement just by a slight lifting, which is easy to operate and save much labor. As the hilly rice fields are scattered on high and low lands, the implements can be quickly disassembled and re-assembled to draw water from different water sources as long as a fulcrum, several bamboo poles and a heavy weight can be found on the high ground, which reflects the convenience of use. There is another kind of water-drawing implements - pulling waterwheel, which is smaller than the pedaling type dumper. Although its water drawing amount is limited, its adaptability is strong, as it can be operated by one person alone. Meanwhile, it has a low fabricating cost, convenient disassembly, and is widely used by a great number of people. In some rural areas, people are still using it nowadays.

The common characteristic of rice farming implements in Eastern Hubei is to attach importance to the functions. In other words, the use of these farming implements is labor saving, time saving, and comfortable. With structure and dimension according with the dimension of human body, rigorously deliberated shape and size, and carefully determined materials and textures at last, they are very scientific even from the perspective of in today's design science. This is of great reference significance for the design of implements in the future.

\section{C. "Unadorned" and "Pure" Decoration}

The folk implements of Eastern Hubei have another major characteristic, which is unadorned without too much decorativeness on most of them. There are too little decoration on them, but it does not mean that people in Eastern Hubei has no ability to create beauty. The bamboo baskets, dustpans, bowl baskets, plowshares and other implements made by people in Eastern Hubei have quite artistic value in their form and texture, which have reflected "the beauty of simplicity". Carvers, when making a plough, consider give various curves to the plough pole, plough tip, and plough dish in the mean time of considering the function of cultivating land, so as to show a beautiful appearance, and make its look clever without showing clumsiness. Miejiangs (craftsmen who make articles from bamboo splits) weave basket cage (bamboo rice farming implements used to contain beans) by bamboo strips and bamboo splits. In weaving, they pay attention to intercalating relationship between bamboo splits. The cage opening adopts flower collar in the shape of Chinese character “人” in single layer. The cage body is woven by a narrow bamboo splits in the way of fictitious graticule. In the weaving process, the geometric pattern with fictitious graticule is structured, which presents a balanced beauty. The woven farming implements like these are often made in a variety of different weaving ways. For example, the large bamboo basket often has an edge closed up in a weaving method of braid, which makes the relatively bald weaving method richer, and also enforces the basket. For winnowing basket, dustpan and other drying implements, Eastern Hubei people weave a triangle, diamond geometry as decoration. Such kind of simple, unadorned but elegant natural beauty contains the simple and pure emotion of Eastern Hubei people, which reflects the unique natural taste as well as the fresh and simple decoration style of the farming implements in Eastern Hubei.

\section{EXPRESSION OF FOLK CULTURE CONTAINED IN THE CUltural HERITAGE OF TRADITIONAL FARMING IMPLEMENTS IN EASTERN HUBEI}

Local farmers in Eastern Hubei experienced the production links of rice cultivation in spring ploughing, summer cultivating, autumn harvesting and winter storage, 
from which they accumulated many different customs. These customs are inseparable from agricultural production and life, and played a very positive role and had a very important role in agricultural production at that time. As an implement item in the production level, the use and inheritance of rice farming implements in Eastern Hubei Province contain rich folk cultural connotations.

\section{A. Labor and Production Customs Formed by Rice Farming Implements in Eastern Hubei}

In land preparation, ploughing and seeding as the initial stage of rice farming, the use customs of farming implements reflect people's expectation of smooth farming. In the old days, the rural areas in Macheng and Huangmei and their surroundings in Eastern Hubei, the lunar second day February is the birthday of plow; on the birthday, the plow was consecrated on the grain field, covering the plow head by red cloth, burning candles and incense and making three kowtows, which was known as "sacrifice plow". Before the first plowing each year, a plowing ceremony was held. People fired three pillars of incense in front of the plow, burned three yellow mounts, made three kowtows, prayed for the solid plow rake and smooth rake, and then began ploughing in the field. On the plowing day, the farming work was arranged easy, to seeking an easy year. Farmers in Huangmei County of Hubei Province set incense table in every household on the first day of spring, prepared farming implements, bought grains, vegetables and other sacrifices, burned incenses and candles, knelt down to greet the spring. ${ }^{2}$ Such custom have continued up to now. It is recorded that at that time, farmers in Hongan County of Hubei Province soaked a small amount of grain seeds in bowls and dishes, and offered them to the god of urn or kitchen to pray for the god to control the seeds. It now appears that the actual effect of this folk custom is to observe the germination rate of rice seeds. After the beginning of summer, it was the large-scale rice transplanting season in Eastern Hubei, in which people generally transplanted rice seedlings before the Grain in Ear Festival for fear of insect infestation later. Every year, the first rice transplanting was called "opening the door of rice seedlings". At this time, people in the rural areas of Ezhou and its surroundings invited teachers to drink wine for planting rice seedlings. The end of transplanting was called "close the door of rice seedlings". At this time, people ended their work early, and had a fancy dinner to celebrate. After rice transplanting, there was also a custom of "plough washing", which was also known as "soil washing" in some places. It was a rice farming custom at the end of the rice transplanting, which meant the plough would not be used until the next year. It gave the villagers a short-term relaxation after hard work. They gathered and drank happily, which physically and mentally brought a joy to them. The harvesting implements in Eastern Hubei were mainly sickles. After the sickles were ground, people used the sickle point to draw a cross on the ground, to avoid "grinding sword", so that they could feel relieved to use. On the first day of using

Edited by the People's Gorvenment of Huangmei County: Annals of Huangmei County [M], Wuhan: Hubei People's Publishing House, 1985, Page 401. the sickle, people sacrificed the god in the field. After eating a meal for sickle opening, farmers went to the field to harvest. It was believed in the folk that the rice barrel was a treasure pot, and the rice barrel would be placed on the side with the mouth of the barrel facing to them to show the harvest surplus. After harvesting and threshing, they pick up the grain with a shovel to remove debris. Before carrying the grain into a granary, they burned candles and incense, worship the god of granary. The grain load was carried by one person without by two persons, as a symbol of good years.

It appears combining the documentary records of local annals and the field investigation results that, the farming folk-custom in Eastern Hubei is closely related to agricultural production, and folk customs arising from the production folk-custom composed of rice farming implements such as plough opening, praying day, seeds praying, rain praying, new tasting and etc are the psychological compensation for the humdrum farming life, in order to meet the deep emotional needs of villagers. With huge social effect, it not just has the function of strengthening the country tradition and linking up the affection of villagers, and more importantly, it also has the function of guiding the agricultural production.

\section{B. Social and Life Folk Customs Formed by Rice Farming Implements in Eastern Hubei}

Many people in Eastern Hubei's countryside have been dealing with grain and rice all their lives. As the implements indispensable in people's daily life, rice farming implements have been deeply integrated into people's life, affecting the traditional festivals in the folk and closely relating to the life customs. Rice farmers give rice farming tools were traded to the spiritual, because rice farm implements the particularity of function, appearance, name, and etc. Various farming implements such as grain sieve, rice bamboo basket, stone roll, stone mill, sickle, hoe and etc have also been given with a certain mysterious power, which can bless people's safety and happiness, from which we can feel more cultural significance. In the process of long-term farming society and activities, rice farming implements has been endowed with abundant folk culture connotation again and again. Combining their roles in production and their visions in life, people have summarized a large number of proverbs, ballads and taboos related to life customs, making it an important carrier of inheriting and spreading the cultural heritage of rice farming implements. As a symbol of farming culture, the folk custom information and deep connotation conveyed from the rice farming implements have revealed the survival logic and production criteria of people in Eastern Hubei.

"Grain sieve" is such a magic tool having the magic power. In ordinary days, it was mainly used to screen chaff to remove husks and retain rice. Because of its densely covered eye holes which were just like thousand-mile eyes, it was regarded as a holy article to keep down demons. After pregnant women produced, they hung a grain sieve in front of their own door with the sieve back outwards, and hung a mirror in the middle, to ward off evil spirits and protect the health of baby; after a baby was born, people sacrificed the 
bed, and placed cakes, grains and other offerings on the grain sieve; making the worship of "one full year of life", the children needed to sit on the grain sieve and had a "grabbing test on the occasion of a baby's first birthday", to protect their safety; The bride is also married to sit on the rice bucket, step the grain sieve, covered the head bead crown to ascend, which implied abundant grain and rice, wealth and happiness. The power of grain sieve to ward off evil and attract good luck is also fully reflected in the beam erecting. In the rural areas of Eastern Hubei, people often hung sickle under the eaves to ward off evil spirits and the sickle is an object of warding off evil and attracting good luck "Having the help from 'grain gods' and 'tian gods', the hoe has the function of driving out evil spirits and protecting production. ${ }^{3}$ Demons and ghosts were afraid to see it and avoided it, so people must carry a hoe when going to draw off the water in the rice fields at night. However, the hoe was protected by the "god of the field", so it could not be stained with feces, wood ash and other dirty things, or it could "have a nightmare". Therefore, there were two holes in the Eastern Hubei farmers' house, of which one was used to hoe the field and the other one was used to mix the ash. Only the hoe used to hoe the field could be used to draw off the water in the field, as it could scared away the ghosts and thus blessed the smooth farming.

\section{VALUE AND ENLIGHTENMENT OF THE CULTURAL HERITAGE OF RICE FARMING IMPLEMENTS IN EASTERN HUBEI}

People in Eastern Hubei have created plentiful and colorful rice farming implements in the long-term labor production, which are the crystallization of wisdom and civilization, the evidence of the development of farming civilization, and the embodiment of the cultural diversity of Eastern Hubei. As a product of history, it has been deeply branded with the imprint of the times. In the process of the long development history, the farming implements of Eastern Hubei, on which the rice farmers recorded the success of ancestors, have recorded the different periods of natural ecological condition, level of productivity, technology capability, the level of the human world, and etc. They also left countless experiences and lessons for future generations. As a part of the whole Chinese rice farming cultural value system, they have the rich historical research value. Accompanied by the folk proverbs, ballads, paintings, poems and other cultural phenomena related to rice farming implements in Eastern Hubei, the fabrication technology, fabrication and use customs, ritual beliefs, life and entertainment and other cultural forms of the rice farming implements are recorded from a unique perspective. With plain and simple patterns, simple colors, touching melody, simple words, a picture scroll of Eastern Hubei's farming style rich in cultural image and cultural feelings is compiled and painted.

Eastern Hubei's long history of rice farming production, in which the process of creating people's material and spiritual wealth is recorded, implies abundant historical culture knowledge and scientific and technological knowledge. It is the visualized carrier of Eastern Hubei's farming culture, and has vivid education appeal. The farming implements have a strong regional style in appearance. It is appealing in design, combines the thick and thin part, and is plain and simple. The "applicable beauty, make the best use of everything" aesthetic taste of the design is reflected from them. Their level of technology has high aesthetic education value. We may integrate the folk tales and production techniques related to farming implements in Eastern Hubei into the school-based curriculum, conduct education of traditional culture in the school, and carry out the publicity and education of the relevant contents in the society, so that young people can understand the value of the cultural heritage of rice farming implements in Eastern Hubei, and establish a scientific concept of cultural heritage.

\section{CONCLUSION}

With the development of mechanized agriculture, many traditional farming methods are unable to adapt to the pace of mechanized agricultural production any more, and have been gradually abandoned and replaced by new methods and new ways. However, can we learn from the concept of "obtaining materials from local resources, adapting measures to local conditions, adapting to local customs, being lowcarbon and environment friendly, and making the best use of everything" from our ancestors, so as to provide reference for our modern agriculture and create more scientific, environment friendly and efficient modern agricultural production tools, and thus promote the comprehensive, coordinated and sustainable development of agricultural economy and society in the old areas.

\section{REFERENCES}

[1] Wang Zheng. Wang Zheng Agricultural Book [M], Beijing: Zhonghua Book Company, 1956. (in Chinese)

[2] Yin Shaoting. Farming Culture - Study on the Origin \& Development and Diversity of Farming implements in Yunnan [M] Nanjing: Yunnan People's Publishing House, Yunnan University Press, 2015. (in Chinese)

[3] Pan Wei. Ancient and Modern Drawings of Traditional Farming Implements of China [M], Kunming: Guangxi Normal University Press, 2015. (in Chinese)

[4] Wang Hu. Design Historiale (Book IV) [M], Nanjing: Jiangsu Arts Publishing House, 2010. (in Chinese).

\footnotetext{
Jiang Bin: Rice Farming Culture and Jiangnan Folk-costom [M], Shanghai: Literatures and Arts Publishing House, 1996, Page 607.
} 